Nig. J. Biotech. Vol. 34 (2017) 117-124

ISSN: 01891731

Available online at

http://www.ajol.info/index.php/njb/index

and www.biotechsocietynigeria.org

DOI: https://dx.doi.org/10.4314/njb.v34i1.15

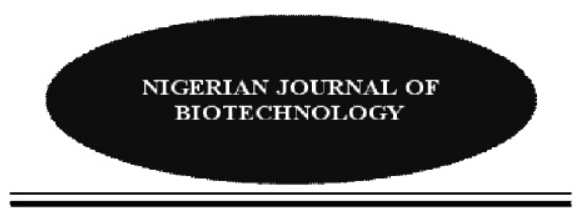

\title{
Effect of dietary inclusion of cashew nut shell liquid on metabolic functions of rumen bacteria in West African dwarf goats
}

\author{
Aderinboye, R. Y., ${ }^{1} *$ Njuguna, J., $^{2}$ Machuka, E., ${ }^{2}$ Adebayo K. O., \\ ${ }^{1}$ Olagoke, K. O., ${ }^{1}$ and Stomeo, $F^{2}$
}

${ }^{1}$ Department of Animal Nutrition, Federal University of Agriculture, Abeokuta, Nigeria ${ }^{2}$ Biosciences Eastern and Central Africa, International Livestock Research Institute, Nairobi, Kenya

Copyright resides with the authors in terms of the Creative Commons License. 4.0.

Condition of use: The user may copy, distribute transmit and adapt the work, but must recognize the authors and the Nigerian Journal of Biotechnology.

\begin{abstract}
This study investigated the effect of dietary inclusion of cashew nut shell liquid (CNSL) on rumen microbial metabolic functions in West African dwarf goats. Twenty-four West African dwarf goats were divided into four groups of six animals each. Each group of animals was fed a basal diet of Panicum maximum and supplemented with one of four concentrate pellets containing CNSL at the rate of $0,2,4$ and $6 \mathrm{ml} / \mathrm{kg}$ in a completely randomized design. Rumen fluid samples ( $n=6 /$ animal) were collected from each animal after 60 days of feeding to assess the rumen metabolic functions in response to CNSL using the 16S rRNA metagenomic approach. Results revealed that the function of ammonia oxidizers was prominent while chitin degradation ranked least. The inclusion of 4 and $6 \mathrm{ml} / \mathrm{kg}$ of CNSL in supplemental diets for goats increased $(P<0.05)$ the function of xylan degraders while ammonia oxidizers, dehalogenation, nitrite reducers, methanogens amongst others were unaltered $(P>0.05)$. It can be concluded that 46 $\mathrm{ml} / \mathrm{kg}$ of CNSL in supplemental pellets for goats enhanced xylan degraders implying higher hemicellulolytic functions which has implication for increased hemicellulose degradation in the rumen.
\end{abstract}

Correspondence:*aderinboyery@funaab.edu.ng

\section{Introduction}

Microorganism in the rumen can be assigned to different functional groups such as cellulolytics, amylolytics, proteolytics, which degrade the wide variety of feed components or further metabolize some of the products formed by other microbes (Henderson et. al., 2015). Although, microorganisms have different metabolic functions within the rumen, these functions are specific to each group of microbes (DAF, 2017). Bacteria are the most abundant microorganisms in the rumen involved in the essential biochemical changes in the rumen (Russell \& Rychlik, 2001). The rumen microbiota in their roles are therefore, considered as an important part of ruminants which shape their nutrition and health (Morgavi et. al., 2015). According to McChann et. al. (2014), diverse microbial community adaptto a wide array of dietary feedstuffs and management strategies. Numerous dietary strategies have consequently been employed to modify rumen function in order to improve animal performance (Dreux, 2017)and a number of plant extracts have gained interest in ruminant nutrition as rumen modifiers (Patra \& Saxena, 2009; Patra, 2011; Flachowsky \& Lebzien, 2012). The mode of action of rumen modifiers is not fully understood but it is assumed to be a result of altering the metabolism of rumen microflora (Solomon, 2014). CNSL, an extract from cashew nut shell has been studied in many in vitro trials with evidence for its regulatory effect on rumen metabolic processes particularly methanogenesis (Watanabe et. al., 2010; Oh et. al., 2017). 
However, limited animal trials have been performed to fully establish its effect on rumen metabolic functions in vivo. The functional characteristics of the microbial community at the genomic level can be studied using the metagenomic approach (Li et. al., 2012). This study therefore, seeks to evaluate the effect of dietary inclusions of CNSL on the metabolic functions of rumen bacteria in West African dwarf goats using the metagenomic approach in order to ascertain its effect on metabolism of goats.

\section{Materials and Methods}

Experimental Site

The experiment was carried out at the Small Ruminant experimental Unit of the Federal University of Agriculture, Abeokuta, Nigeria and the Biosciences Eastern and Central Africa, International Livestock Research Institute (BecA-ILRI) laboratory, Nairobi, Kenya.

\section{Animal feeding and rumen sampling}

Twenty-four West African dwarf growing goats weighing between 10 and $15 \mathrm{~kg}$ were used for this study. All experimental procedures and handling with the goats received prior approval from the Small Ruminant Technical Committee of the College of Animal Science and Livestock Production, Federal University of Agriculture, Abeokuta and were in line with International standards. The animals were housed in wellventilated pens and allowed a stabilization period of one month during which they were maintained on grass, concentrate supplement and water ad libitum. At the end of the stabilization period, they were divided into four groups of six animals each and each group randomly assigned to one of four supplemental pellet containing varying levels of CNSL at 0 (control diet), 2, 4 and $6 \mathrm{ml} / \mathrm{kg}$ with Panicum maximum as basal diet (Table 1). The basal diet was supplied ad libitum while the pellets were given at $3 \%$ of animal's body weight. Animals were fed for a 60day period. Rumen fluid samples were collected from each animal through suction method in the morning on day 60 , three hours after feeding. Collected samples were strained through four-layered cheese cloth. About $10 \mathrm{ml}$ of rumen fluid was collected into sampling tubes and immediately

Table 1. Ingredient and nutrient composition of experimental diets

\begin{tabular}{|c|c|c|c|c|c|}
\hline \multirow{2}{*}{$\begin{array}{l}\text { Ingredient composition, } \mathbf{g} \mathbf{~ k g} \\
\mathrm{DM}^{-1}\end{array}$} & \multicolumn{5}{|c|}{$\begin{array}{l}\text { Supplemental pellets with cashew nut } \\
\text { shell liquid }\end{array}$} \\
\hline & $\mathbf{0 ~ m l}$ & $2 \mathrm{ml}$ & $4 \mathrm{ml}$ & $6 \mathrm{ml}$ & Panicum maximum \\
\hline Wheat offal & 670.0 & 670.0 & 670.0 & 670.0 & - \\
\hline Brewers' dried grain & 300.0 & 300.0 & 300.0 & 300.0 & - \\
\hline Bone meal & 20.0 & 20.0 & 20.0 & 20.0 & - \\
\hline Salt & 10.0 & 10.0 & 10.0 & 10.0 & - \\
\hline Cashew nut shell liquid ${ }^{\mathbf{1}}$ & - & + & ++ & +++ & - \\
\hline Total & $1000 \mathrm{~g}$ & $1000 \mathrm{~g}$ & $1000 \mathrm{~g}$ & $1000 \mathrm{~g}$ & - \\
\hline \multicolumn{6}{|l|}{$\begin{array}{l}\text { Nutrient composition, } \mathbf{g} \mathbf{~ k g} \\
\mathrm{DM}^{-1}\end{array}$} \\
\hline Dry matter ${ }^{2}$ & 97.81 & 97.11 & 97.00 & 96.86 & 38.60 \\
\hline Crude protein & 16.82 & 16.60 & 16.58 & 16.54 & 8.20 \\
\hline Ether extract & 7.62 & 8.24 & 8.37 & 8.41 & 3.0 \\
\hline Ash & 9.46 & 9.44 & 9.38 & 9.40 & 6.85 \\
\hline Organic matter & 90.54 & 90.56 & 90.62 & 90.60 & 93.15 \\
\hline Neutral detergent fibre & 42.56 & 41.81 & 41.63 & 42.11 & 56.60 \\
\hline Acid detergent fibre & 14.41 & 14.34 & 14.12 & 14.38 & 28.75 \\
\hline Lignin & 6.46 & 6.52 & 6.55 & 6.60 & 12.42 \\
\hline $\mathrm{ME}(\mathrm{MJ} / \mathrm{kg} \mathrm{DM})^{3}$ & 12.67 & 12.69 & 12.69 & 12.69 & 12.36 \\
\hline
\end{tabular}

${ }^{1}$ Cashew nut shell liquid was included as feed additive in complete concentrate pellets at levels of $0(-), 2(+), 4(++)$ and $6(+++) \mathrm{ml} / \mathrm{kg} \mathrm{DM} ;{ }^{2}$ Dry matter on As-fed basis; ${ }^{3} \mathrm{ME}=12.86+0.0265 \mathrm{FAT}$ -0.0056ADF-0.0153ASH-0.0253ADL (De Boever, 1997) 


\section{Chemical analysis}

Aliquot samples of the experimental feed offered were oven-dried at $65^{\circ} \mathrm{C}$ to constant weight for dry matter determination. Oven-dried samples were then milled and used for determination of proximate (A. O. A. C. 2000) and fibre (Van Soest et. al., 1991) composition. Metabolizable energy content of the diets was estimated following the formula of De Boever (1997).

\section{DNA extraction}

Total genomic DNA from rumen fluid samples was extracted using the ZR Soil Microbe DNA MiniPrep $^{\mathrm{TM}}$ kit (Catalog No. D6001, Zymo Research Corp.), following manufacturer's protocol. The genomic DNA concentration and quality was checked using a NanoDrop spectrophotometer (Thermo Scientific 2000c) and gel electrophoresis ( $0.8 \%$ agarose gel), respectively. The genomic DNA was diluted to a final concentration of $20 \mathrm{ng} / \mu \mathrm{L}$ and then stored at $-20^{\circ} \mathrm{C}$ for PCR amplification.

\section{PCR amplification procedure}

The V3 V4 hyper-variable regions of the 16S rRNA gene were amplified from genomic DNA following the 16S rRNA amplification procedure of Caporaso et. al. (2012). The primer set used was $515 f$ ( 5 ' GTGCCAGCMGCCGCGGTAA-3') and 806r (5' GGACTACHVGGGTWTCTAAT-3') with twelve Golay barcodes to allow multiplexing. The PCR amplification for each sample was done in duplicates of $50 \mu \mathrm{L}$ reaction mixture containing $25 \mu \mathrm{L}$ of premix (Bioneer Accupower premix in solution), $1.5 \mu \mathrm{L}$ of each primer with the reverse primer unique to each sample, $5 \mu \mathrm{L}$ of $20 \mathrm{ng}$ template DNA and $17 \mu \mathrm{L}$ nuclease free water. Thermo cycling procedures used were initial denaturation at $94^{\circ} \mathrm{C}$ for $3 \mathrm{~min}, 35$ cycles of denaturation at $95^{\circ} \mathrm{C}$ for $30 \mathrm{sec}$, annealing at $55^{\circ} \mathrm{C}$ for $30 \mathrm{sec}$, elongation at $72^{\circ} \mathrm{C}$ for $30 \mathrm{sec}$, a final extension at $72^{\circ} \mathrm{C}$ for $5 \mathrm{~min}$ and a holding temperature at $20^{\circ} \mathrm{C}$. The presence of the targeted DNA region was confirmed on $1.8 \%$ agarose gel. The duplicates of the PCR products per sample were then pooled and purified using the QIAquick PCR purification kit (Catalog No. 28106, Qiagen, Germany, 250 assay). The quality of the purified amplicons was checked on $1.8 \%$ agarose gel and quantification was done by Qubit assay using the Qubit $\AA$ dsDNA HS (High Sensitivity) Assay Kits prior to sequencing. Sequencing

The library preparation for sequencing was done by pooling amplicon from each sample into a single sterile tube at equimolar concentration of $40 \mathrm{ng}$ of DNA per sample. The final quantification and quality check of the pool was done using the Qubit assay and the agilent tape station. The pooled barcoded amplicons were then sequenced using the pair-end method on the illumina Miseq platform. The resulting sequences and quality score data were extracted from the fastq files for further downstream analysis.

Bioinformatics and statistical analysis

The resulting sequences from the fastq files were screened and filtered for quality and length using QIIME. Sequences with a read length longer than $253 \mathrm{bp}$, having more than two primer mismatches, containing ambiguous characters, exhibiting a homopolymer greater than $8 \mathrm{bp}$ in length or had an average quality score of less than 25 were removed. The high-quality sequences were then clustered into operational taxonomic units (OTUs) defined by $97 \%$ similarity. The OTU picking was performed using the open-reference OTU picking protocol of QIIME. Taxonomic assignments of OTUs that reached $97 \%$ similarity level were done by comparison with the Green gene (http://greengenes.secondgenome.com/) database using QIIME. The relative abundance of dominant OTUs were compared across treatment groups using the one-way analysis of variance and mean differences separated using Tukey's HSD (SPSS, 2011). The phenotypic characteristic based on metabolism of the classified OTUs was assessed with METAGENassist statistical tool for comparative metagenomics (Arndt et. al., 2012) which maps OTUs to phenotypic categories. Metabolic functions of OTUs were compared across the groups with the use of bar charts excluding categories with less than $0.1 \%$. A one-way analysis of variance using METAGENassist (Arndt et. al., 2012) was used to determine statistical significance on changes in the metabolic functions of OTUs in response to dietary CNSL. Level of significance was set at 5\% and post-hoc analysis was done using Tukey's HSD (Arndt et. al., 2012). 


\section{Results}

A total of $8,957,483$ quality sequences were obtained from 144 samples collected from the twenty-four goats with an average of 62,205 reads per sample. The total number of OTUs detected up to species level was 17,034 . The OTUs were assigned to 33 different phyla and the dominant phyla included the Euryarchaeota, Actinobacteria, Bacteroides, Firmicutes, Proteobacteria, Spirochaetes and Verrucomicrobia which represented $96 \%$ of the total OTUs. The relative abundance $(P>0.05)$ of the OTUs at phylum level are presented in Table 2.

Table 2: Relative abundance of dominant operational taxonomic units (OTUs) identified in rumen of goats fed supplemental pellets containing varying levels of cashew nut shell liquid

\begin{tabular}{|c|c|c|c|c|c|c|}
\hline OTUs ${ }^{1}$ & $0 \mathrm{ml} / \mathrm{kg}$ & $2 \mathrm{~m} / \mathrm{kg}$ & $4 \mathrm{ml} / \mathrm{kg}$ & $6 \mathrm{~m} / \mathrm{kg}$ & SEM $^{2}$ & $p$-value \\
\hline \multicolumn{7}{|l|}{ Archaea } \\
\hline Euryarchaeota & 8441.39 & 8240.22 & 10805.06 & 6799.54 & 849.10 & 0.345 \\
\hline \multicolumn{7}{|l|}{ Bacteria } \\
\hline Actinobacteria & 6980.33 & 6968.39 & 13063.44 & 9150.71 & 998.80 & 0.133 \\
\hline Bacteroidetes & 21366.92 & 17556.86 & 16236.22 & 17754.17 & 1518.36 & 0.635 \\
\hline Firmicutes & 23513.19 & 23054.86 & 21736.31 & 18226.03 & 1624.05 & 0.662 \\
\hline Proteobacteria & 314.81 & 339.17 & 406.03 & 239.43 & 43.49 & 0.534 \\
\hline Spirochaetes & 1428.33 & 1878.28 & 1268.28 & 1573.83 & 192.22 & 0.681 \\
\hline Verrucomicrobia & 434.42 & 232.08 & 182.19 & 220.40 & 36.39 & 0.066 \\
\hline
\end{tabular}

${ }^{1}$ OTUs mean relative abundance at phylum level;

${ }^{2} \mathrm{SEM}$ : standard error of mean

Metabolic functions associated with the OTUs in the rumen of goats fed varying levels of CNSL is presented in Figure 1. In samples from the control group (Figure 1 a), taxonomic-tophenotype mapping revealed the presence of ammonia oxidizers (48.6\%), bacteria associated with dehalogenation $(44.5 \%)$, sulfide oxidizer $(43.0 \%)$, nitrite reducers $(30.9 \%)$, sulfate reducers $(27.5 \%)$, cellulose degraders $(15.5 \%)$, methanogens $(13.9 \%)$, xylan degraders $(13.3 \%)$ amongst other minute functions such as chitin degradation and nitrogen fixation. Similar metabolic functions were observed in goats fed pellets containing $26 \mathrm{ml} / \mathrm{kg}$ of CNSL (Figure $1 \mathrm{~b}$, c, and d).
CnsL: 0

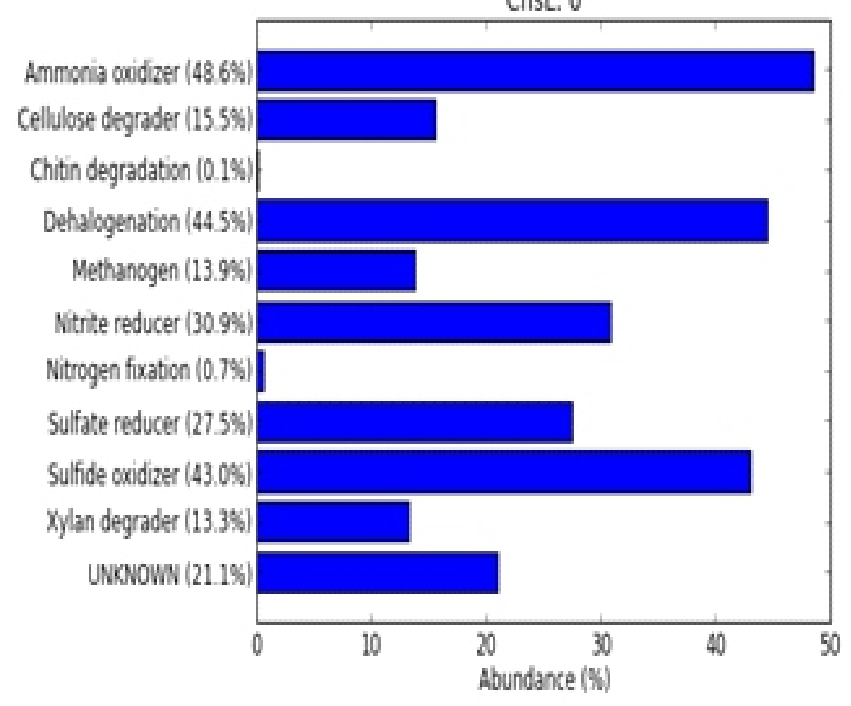

Cnst: 2

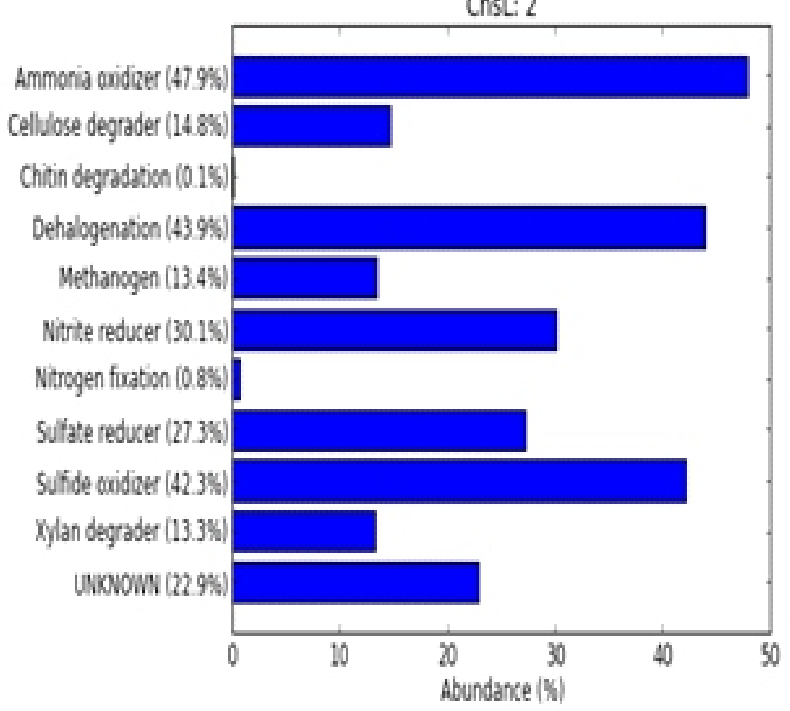


Cnst: 4

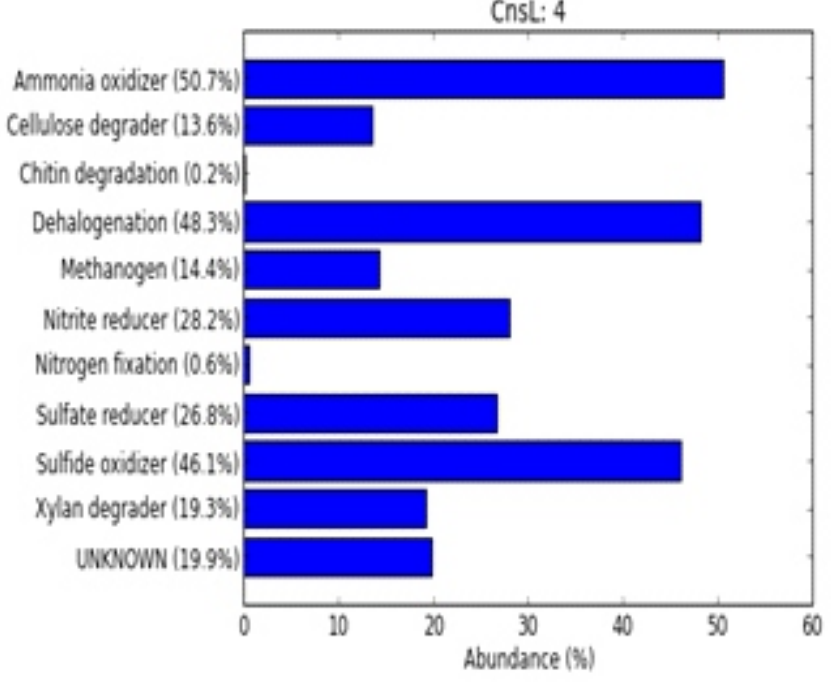

CnsL: 6

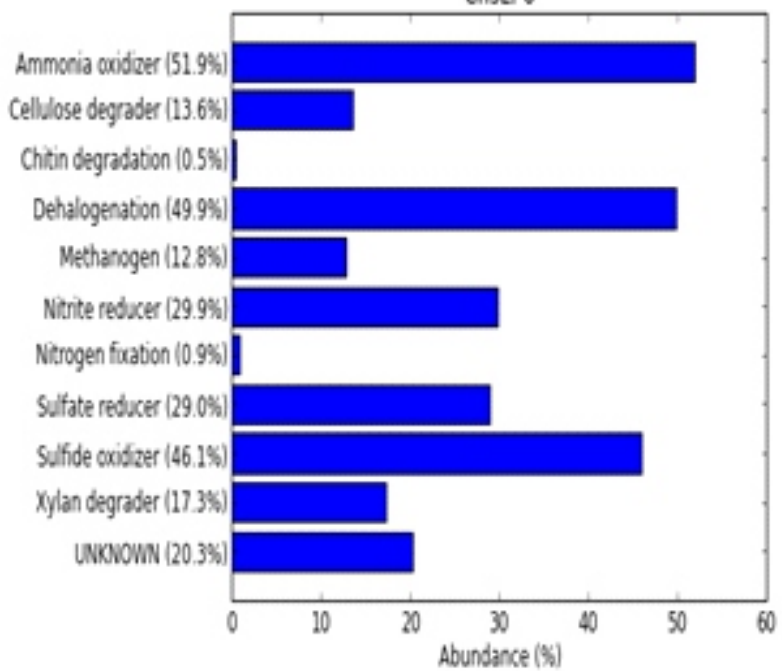

Figure 1: Metabolic functions of rumen bacteria in WAD goats fed cashew nut shell liquid in supplemental diet at levels of (a) $0 \mathrm{ml} / \mathrm{kg}$, control diet (b) $2 \mathrm{ml} / \mathrm{kg}$ (c) $4 \mathrm{ml} / \mathrm{kg}$ and (d) $6 \mathrm{ml} / \mathrm{kg}$

Variations in metabolic functions (features) of the OTUs in response to CNSL is shown in Figure 2. All but one of the functions were not affected $(P>0.05)$ by feeding CNSL in supplemental pellets at $26 \mathrm{ml} / \mathrm{kg}$ (Figure 2a). The feature details (Figure $2 b$ ) revealed an increase $(P<$ $0.05)$ in metabolic function of xylan degraders in rumen of goats fed 4 and $6 \mathrm{ml} / \mathrm{kg}$ of CNSL relative to the control. Ammonia and sulfide oxidizers, nitrite and sulfate reducers, cellulose degraders, methanogens, chitin degradation and nitrogen fixation function were however, not affected $(P>0.05)$ with dietary inclusion of CNSL.
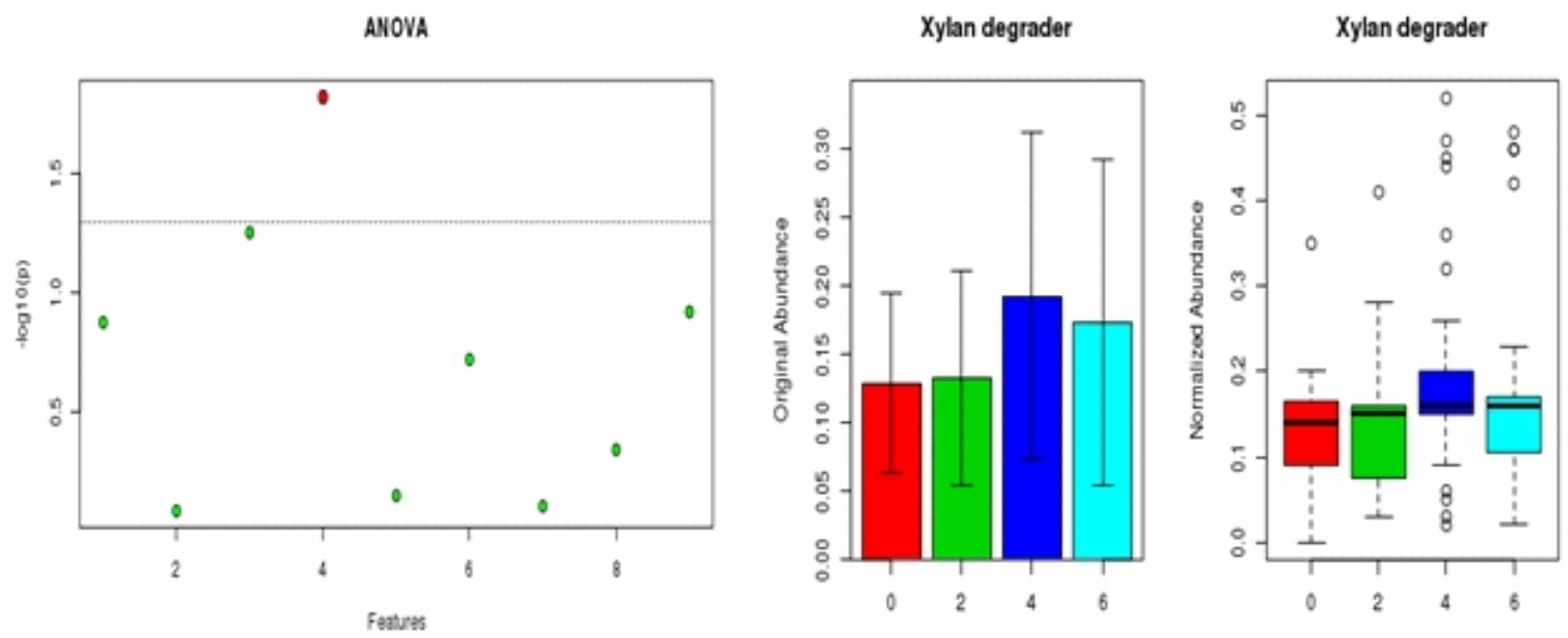

Figure 2: (a) One-way analysis of variance (ANOVA) plot with red dots indicating significant $(P<0.05)$ features scoring above a given threshold (the horizontal dotted line) (b) Feature details of metabolic function with significant variation in response to dietary inclusion of cashew nut shell liquid at 0, 2, 4 and $6 \mathrm{ml} / \mathrm{kg}$

\section{Discussion}

Although, bacteria population was targeted in our study, the $515 \mathrm{f} / 806 \mathrm{r}$ primer set used also identified archaea taxa. According to Thijs et. al. (2017), these prokaryotic primer sets have been optimized to target both bacteria and archaea groups. Xylan is a major component of hemicellulose (Menon et. al., 2010) and the increase in xylan degraders at 4 and $6 \mathrm{ml} / \mathrm{kg}$ of
CNSL suggests an increase in breakdown of hemicellulose, a fraction of dietary fibre, thus indicating a possible influence of CNSL on hemicellulolytic activities.

Stability of ammonia oxidizers and nitrite reducers implied that the levels of CNSL used in this study did not affect nitrification, the process by which ammonia is oxidized to nitrite (Ward, 
2013). This process occurs mostly under aerobic conditions and is initiated by a proteobacteria known as Nitrosomonas species. Nitrosomonas spp. Have however been identified in the rumen as epimural bacteria, inhabiting the highly oxygenated rumen walls and their roles have been considered as strategically important even though they do not make significant contribution to ruminal digestion (Mitsumori et. al., 2002; Nagaraja, 2016). Biohydrogenation which was similarly not affected in this study implied that biohydrogenation was not controlled with inclusion of $26 \mathrm{ml} / \mathrm{kg} \mathrm{CNSL}$. Biohydrogenation is a unique biological process prevalent in the rumen microbial ecosystem in which unsaturated fatty acids are converted to more saturated end products by gut microbes (Li et. al., 2012).

If ruminal biohydrogenation of unsaturated fatty acids can be controlled, it may be possible to improve the healthiness of ruminant meats and milk by increasing their unsaturated fatty acids composition in general and the $n-3$ fatty acids in particular (Maia et. al., 2010). The stability in other metabolic functions of rumen bacteria in our study possibly suggested that the level of CNSL in the diet were below the concentrations at which inhibition, stimulation or modifications of these processes in the rumen could be achieved. Although studies on the effect of CNSL on metabolic functions of rumen microbes is scarce in literature, the reported inhibitory effect of CNSL on methanogenesis (Watanabe et. al., 2010; Shinkai et. al., 2012; Kobayashi et. al., 2016) was not observed in this study as methanogen functions remained unaltered. It could be assumed therefore, that energy metabolism within the rumen was not modified by dietary inclusion of $2-6 \mathrm{ml} / \mathrm{kg}$ CNSL in supplemental diet. Cashew nut shell liquid has been considered as a potent agent for modifying rumen fermentation patterns in vitro (Watanabe et. al., 2010), but its effect in vivo could be dosedependent.

\section{Conclusion}

From our study, CNSL at $4-6 \mathrm{ml} / \mathrm{kg}$ in supplemental pellets for goats enhanced xylan degraders while other metabolic functions in the rumen were not altered with CNSL. The higher activity of xylan degraders portrays that CNSL could influence hemicellulolytic functions in the rumen which has implication for hemicellulose degradation. Activity of rumen microbes in response to higher levels of dietary inclusion in the diet could be further investigated.

\section{Acknowledgement}

This project is part of a full project sponsored by the African Women in Agricultural Research and Development (AWARD), Nairobi, Kenya and the Biosciences Eastern and Central Africa, International Livestock Research Institute (BecAILRI), Nairobi, Kenya through the ABCF Program funded by the Australian Department for Foreign Affairs and Trade (DFAT) through the BecA-CSIRO partnership; the Syngenta Foundation for Sustainable Agriculture (SFSA); the Bill \& Melinda Gates Foundation (BMGF); the UK Department for International Development (DFID) and the Swedish International Development Cooperation Agency (Sida).

\section{References}

Arndt, D., Xia, J., Liu, Y., Zhou, Y., Guo, A. C., Cruz, J. A., Sinelnikov, I., Budwill, K., Nesbo, C. L., and Wishart D. S. 2012. METAGENassist: A comprehensive web server for comparative metagenomics. Nucleic Acids Res. 40 (Web Server issue ): W88-95. DOI : $10.1093 /$ nar/gks497

A. O. A. C., 2000. Official methods of analysis of AOAC. International 17th edition; Gaithersburg, MD, USA.

Caporaso, J. G., Lauber, C. L., Walters, W. A., Berg-Lyons, D., Huntley, J., Fierer, N., Owens, S. M., Betley, J., Fraser, L., Bauer, M., Gormley, N., Gilbert, J. A., Smith, G. and Knight, R. (2012). Ultra-high-throughput microbial community analysis on the Illumina HiSeq and MiSeq platforms. ISME J. 6, 16211624. DOI: 10.1038/ismej.2012.8

DAF. 2017. The vital role of rumen microbes. Nutrition for lactating dairy cows. Department of Agriculture and Fisheries. Queensland

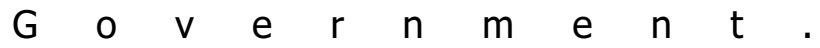
https://www.daf.qld.gov.au/animalindustries/dairy/feed-and-nutrition/nutritionfor-lactating-dairy-cows/rumen-microbes accessed 27 December, 2017 
DeBoever, J. L., Cottyn, B. G., DeBrabandar, D. L., Vanacker, J. M. and Boucque, C. V. 1997. Prediction of the feeding value of maize silage by chemical parameters, in vitro digestibility and near infra-red spectroscopy (NIRS). Anim. Feed Sci. Technol. 66: 211 - 222.

Dreux, D. 2017. Rumen manipulation. http://www.keenansystem.com/ieen/2017/10/31/rumen-manipulation/ accessed 27 December 2017

Flachowsky, G and Lebzien, P. 2012, Effects of phytogenic substances on rumen fermentation and methane emissions: A proposal for a research process. Anim. Feed Sci. Technol. 176: $70-77$

Henderson, G., Cox, F., Ganesh, S., Jonker, A., Young, W., Global Rumen Census Collaborators and Janssen, $\mathrm{P}, \mathrm{H}, 2015$. Rumen microbial community composition varies with diet and host, but a core microbiome is found across a wide geographical range. Scientific Reports5 (14567.1-14567): 13 pp. DOI : $10.1038 / \mathrm{s} r$ e p 145567 www.nature.com/articles/srep14567

Kobayashi, Y., Oh, S., Myint, H. and Koike, S. 2016. Use of Asian selected agricultural byproducts to modulate rumen microbes and fermentation. J. Anim. Sci. Biotechnol.7: 70. DOI 10.1186/s40104-016-0126-4

Li, D., Wiang, J. Q. and Bu, D. P. 2012. Rumen microbe of biohydrogenation of trans-vaccenic acid to stearic acid in vitro. BMC Research Notes 5: 97 http://www.biomedcentral.com/17560500/5/97

Maia, M. R. G., Chaudhary, L. C., Bestwick, C. S., Richardson, A. J., McKain, N., Larson, T. R., Graham, I. A. and Wallace, R. J. 2010. Toxicity of unsaturated fatty acids to the biohydrogenating ruminal bacterium, Butyrivibrio fibrisovens. BMC M i c robiol. $10: 52$ http://www.biomedcentral.com/1471 2180/10/52

Manon, V., Prakash, G. and Rao, M. 2010. Value added products from hemicellulose:
Biotechnological perspective. http://ncl.csircentral.net/1138/1/Value_added_ products_from_hemicellulose.pdf accessed 31 December, 2017

McCann, J. C., Wickersham, T. A. and Loor, J. J. 2014. High-throughput Methods Redefine the Rumen Microbiome and Its Relationship with Nutrition and Metabolism. Bioinform. Biol. Insights. 8: 109125.DOI: 10.4137/BBI.S15389

Mitsumori, M., Ajisaka, Tajima, K., Kajikawa, H. and Kurihara, M. 2002. Detection of Proteobacteria from the rumen by PCR methanotroph-specific primers. Lett. Appl. Microbiol. 35: 251 - 255

Morgavi, D. P., Paris, E. R., Popova, M., Boccard, J., Nielsen, K. F. and Bouda, H. 2015. Rumen microbial communities influence metabolic phenotypes in lambs. Front. Microbiol. DOI: 10.3389/fmicb. 2015.01060

Nagaraja, T. G. 2016. Microbiology of the rumen. In: D. D. Millen, R. D. L. Pacheco and M. D. B. Arrigoni (eds.). Rumenology. Springer International publishing Switzerland. Pp. 3961 DOI 10.1007/978-3-319-30533-2

Oh, S., Suzuki, Y., Hayashi, S., Suzuki, Y., Koike, S. and Kobayashi, Y. 2017. Potency of cashew nut shell liquid in rumen modulation under different dietary conditions and indication of its surfactant action against rumen bacteria. J. Anim. Sci. Technol. 59: 27 DOI 10.1186/s40781-017-01508

Patra, A. and Saxena, J. 2009. Dietary phytochemicals as rumen modifiers: a review of the effects on microbial population. Antonie van Leeuwenhoek 96(4):363-75 DOI: $10.1007 / \mathrm{s} 10482-009-9364-1$

Patra, A. K. 2011. Effects of Essential Oils on Rumen Fermentation, Microbial Ecology and Ruminant Production. Asian J. Anim. Vet. Adv.6: 416 - 428.

Russell, J. and Rychlik, J. 2001. Factors that alter rumen microbial ecology. Science 292 (5519): 11191122 DOI: $10.1126 /$ science. 1058830. 
Shinkai, T., Enishi, O., Mitsumori, M., Higuchi, K., Kobayashi, Y., Tak-enaka, A., Nagashima, K., Mochizuki, M. and Kobayashi, Y. 2012. Mitigation of methane production from cattle by feeding cashew nut shell liquid. J. Dairy Sci.95: 5308 5316

Solomon, M. B. 2014. Effect of animal production on meat quality. In: F. Shahidi, A. M. Spanier, C. T. Ho, T. Braggins (eds.). Quality of fresh and processed foods. Advances in experimental medicine and biology. Springer media+Business Media NY, Pp. 123.

SPSS. 2011. IBM Corp. Released 2011. IBM SPSS Statistics for Windows, Version 20.0. Armonk, NY: IBM Corp.

Thijs, S., Beeck, M. O. D., Beckers, B., Truyens, S., Stevens, V., Hamme,J. D. V., Weyens, N. and Vangronsveld' J. 2017. Comparative Evaluation of
Four Bacteria-Specific Primer Pairs for 16S rRNA Gene Surveys. Front. Microbiol. 8: 494. DOI: 10.3389/fmicb.2017.00

Van Soest, P.J., Robertson, P.J. and Lewis, B.A., 1991. Methods for dietary fiber, neutral detergent fiber, and non-starch polysaccharides in relation to animal nutrition. J. Dairy Sci. 74: 3583 - 3597.

Ward, B. B. 2013. Nitrification. Elsevier Inc., 8 pp. https://www.princeton.edu/nitrogen/publicatio ns/pdfs/Ward_2015_Nitrification.pdf accessed 31 December, 2017

Watanabe, Y.; Suzuki, R.; Koike, S.; Nagashima, K.; Mochizuki, M.; Forster, R.J. and Kobayashi, Y. 2010. In vitro evaluation of cashew nut shell liquid as a methane-inhibiting and propionateenhancing agent for ruminants. J. Dairy Sci. 93: 5258 - 5267. 